\title{
Rough-bed flows in geophysical, environmental, and engineering systems: Double-Averaging Approach and its applications
}

\author{
PREFACE TO THE SPECIAL ISSUE
}

\author{
Vladimir I. NIKORA ${ }^{1}$ and Paweł M. ROWIŃSKI ${ }^{2}$ \\ ${ }^{1}$ School of Engineering, University of Aberdeen, Scotland, UK \\ e-mail: v.nikora@abdn.ac.uk \\ ${ }^{2}$ Institute of Geophysics, Polish Academy of Sciences, Warszawa, Poland \\ e-mail: pawelr@igf.edu.pl
}

Rough-wall turbulent flows represent a ubiquitous feature of many natural systems and man-made structures and therefore they have attracted significant attention from mathematicians, physicists, engineers, and Earth scientists, who have extensively studied these flows for more than eighty years. However, in spite of a fairly long research history and significant progress made towards their description and understanding, accurate prediction and control of rough-wall flows are still unsolved problems and thus additional research efforts and new approaches are required. One of these approaches, the so-called Double-Averaging Methodology (DAM), is the topic of this Special Issue.

Current research focuses on two interlinked facets of the rough-wall flows, statistical and deterministic. The deterministic view stems from some observable 'coherency' in the turbulent motions and from hydrodynamic equations based on fundamental conservation principles, while the statistical view recognises 'irregular' components in hydrodynamic fields and roughwall geometry and therefore focuses on their statistical properties. Both fa-

(C) 2008 Institute of Geophysics, Polish Academy of Sciences 
cets can be combined within a framework of appropriately averaged hydrodynamic equations, of which the well-known Reynolds-Averaged NavierStokes equations (RANS) are an example. However, the RANS incorporate no spatial averaging making them inconvenient for characterising rough-wall flows. This is especially true for the near-wall region where time-averaged flow is highly heterogeneous due to local effects of roughness elements. Indeed, local (point) flow parameters provided by the RANS cannot be linked explicitly to somewhat spatially-averaged roughness parameters and hydrodynamic processes which are the subjects of most engineering and environmental applications. The highlighted scale inconsistency can be eliminated by supplementing the time (ensemble) averaging of the hydrodynamic equations with volume averaging or area averaging in the plane parallel to the mean (smoothed) bed surface. This leads to a new set of hydrodynamic equations, which are averaged in both time (ensemble) and space domains. These equations explicitly contain important (although still unconventional) terms such as form-induced (also known as 'dispersive') stresses and fluxes, and, for the flow region below roughness tops, form and viscous drag terms, wake and waving production terms (e.g., turbulent energy production due to wake effects behind bed surface mounds or due to mobile interfaces such as plants or other organisms), and source/sink terms describing interface transport and heterogeneous reactions (e.g., sediment 'breathing' or nutrient uptake by aquatic organisms). The double-averaging (i.e., in time and space) approach extends a set of available tools for flow analyses especially over rough boundaries. Examples of advantages that this approach provides include: (a) improved hydraulic definitions (e.g., flow uniformity, twodimensionality, and the bed shear stress); (b) consistent coupling between spatially-averaged roughness parameters, bed shear stress, and doubleaveraged flow variables; (c) explicit accounting for the viscous drag, form drag and form-induced stresses and substance fluxes as a result of rigorous derivation rather than intuitive reasoning; (d) possibilities for similarity and scaling considerations based on double-averaged variables; and (e) possibilities for the consistent scale partitioning of the roughness parameters and flow properties.

The double-averaging methodology has extensive roots in multi-phase flow hydrodynamics (e.g., Whitaker 1999, Slattery 1999) and porous-media hydrodynamics (e.g., Bear 1972, de Lemos 2006). Its formulation for roughwall turbulent flows has been initiated by atmospheric scientists for describing and predicting turbulent flows within and above terrestrial canopies such as forests or bushes (Wilson and Shaw 1977, Raupach and Shaw 1982, Finnigan 1985, 2000). In fluvial hydraulics, the idea of spatial averaging was first used by Smith and McLean (1977) who analysed velocity profiles spatially averaged along lines of constant distance from the wavy bed. Recent developments in fluvial hydraulics followed the meteorological approach 
where averaging has been implemented within Cartesian coordinates (e.g., Gimenez-Curto and Corniero Lera 1996, Lopez and Garcia 1998, 2001, McLean et al. 1999, Nikora et al. 2001, 2007a,b, Maddux et al. 2003, Hoffman 2004, Manes et al. 2007, Pokrajac 2007, 2008). To explore the potential of this approach for wider geophysical, environmental, and engineering applications, a series of informal international workshops has been initiated and the term 'double-averaging methodology' with abbreviation 'DAM' has been introduced to label this approach. As a result of this collective effort, six DAM workshops have already been held (Belgium/Wavre 2002, Greece/Thessalonica 2003, Spain/Madrid 2004, Scotland/Aberdeen 2005, Portugal/Lisbon 2006, Castelfranco/Italy 2007), and the next workshop is planned to be held in Çeşme/Turkey (2008). As a result, an active collaborative network has been formed involving more than forty researchers from Canada, India, Italy, France, Germany, New Zealand, Poland, Portugal, UK, and USA. The work progress has been reported and discussed in two recent papers in ASCE Journal of Hydraulic Engineering (Nikora et al. 2007a,b) where the main focus was on fluvial systems. To extend the scope and the range of applications, the participants of the fifth DAM Workshop in Lisbon (2006) decided that it would be beneficial to prepare a special collection of papers covering a wider variety of problems and flow configurations. This Issue, thus, is an implementation of that decision. All papers in the Issue are invited and have been accepted through a rigorous review process, which would not be possible without the help of a large number of international experts. Although the Issue has been initiated by fluvial researchers and thus is dominated by fluvial papers, it also includes papers from atmospheric and porous media researchers thus providing a wider perspective. This discipline diversity unavoidably means some diversity in symbols, which we have not removed to preserve discipline flavour and historical roots. This, however, should not introduce any difficulty as all symbols in the papers are clearly defined.

The use of DAM in hydraulics is growing and it has been already successfully used by a number of research groups worldwide for developing numerical models, designing experiments, data analysis and interpretation, and guiding conceptual developments and parameterizations. The current research trend suggests that the DAM may soon become a standard tool for flow researchers and this Issue reflects this tendency. The Issue includes nineteen papers which can be grouped into six subsets. First subset includes two review papers from J. Finnigan and R. Shaw (atmospheric canopy flows) and M. de Lemos (flows in porous media). These papers provide an excellent background useful for fluvial considerations and complementary to fluvial review papers recently published in ASCE Journal of Hydraulic Engineering (Nikora et al. 2007a, b). The second subset covers studies of gravel-bed flows and flows over beds formed by beads that simulate gravel 
(J. Aberle, F. Ballio, E. Barthelemy, S. Cameron, S. Coleman J. Cooper, A. Dittrich, D. Hurther, K. Koll, E. Mignot, V. Nikora, A. Radice, and S. Tait). These papers are followed by papers of S. Coleman, S. Lanzoni, S. McLean, V. Nikora, and T. Schlicke, which may be most closely associated with sand-bed flows and thus form the third subset. The fourth subset relates to flows over vegetated beds with papers from M. Ghisalberti, G. Katul, H. Nepf, D. Poggi, and M. Righetti, who are leading researchers in this area. The main focus of papers by O. Coceal, C. Manes, I. McEwan, and D. Pokrajac is on surface-subsurface exchanges and form-induced momentum fluxes (fifth subset). The distinct feature of the last, sixth, group of papers is that they either use numerical simulations to study double-averaged flow properties (S.E. Belcher, O. Coceal, V. Nikora, T. Stoesser, and T.G. Thomas), or use the double-averaged equations as the basis for numerical models and simulations (D. Plew, P. Prinos, D. Souliotis, and R. Walters).

We hope that this Issue will be a useful step forward in further development and promotion of the Double-Averaging Methodology and its geophysical, environmental, and engineering applications.

\section{References}

Bear, J. (1972), Dynamics of Fluids in Porous Media, Elsevier, New York.

de Lemos, M.J.S. (2006), Turbulence in Porous Media. Modeling and Applications, Elsevier, Amsterdam.

Finnigan, J.J. (1985), Turbulent transport in flexible plant canopies. In: B.A. Hutchinson and B.B. Hicks (eds.), The Forest-Atmosphere Interactions, D. Reidel Publishing Company, 443-480.

Finnigan, J.J. (2000), Turbulence in plant canopies, Ann. Rev. Fluid Mech. 32, 519571.

Gimenez-Curto, L.A., and M.A. Corniero Lera (1996), Oscillating turbulent flow over very rough surfaces, J. Geophys. Res. 101, C9, 20,745-20,758.

Hoffmann, M.R. (2004), Application of a simple space-time averaged porous media model to flow in densely vegetated channels, J. Porous Media 7, 183-191.

Lopez, F., and M.H. Garcia (1998), Open-channel flow through simulated vegetation: suspended sediment transport modelling, Water Resour. Res. 34, 9, 2341-2352.

Lopez, F., and M.H. Garcia (2001), Mean flow and turbulence structure of openchannel flow through emergent vegetation, J. Hydraul. Eng. ASCE 127, 5, 392-402. 
Maddux, T.B., S.R. McLean, and J.M. Nelson (2003), Turbulent flow over threedimensional dunes. 2: Fluid and bed stresses, J. Geophys. Res. 108, F1, 6010, DOI: 10.1029/2003JF000018, 2003.

Manes, C., D. Pokrajac, and I. McEwan (2007), Double-averaged open-channel flows with small relative submergence, J. Hydraul. Eng. 133, 8, 896-904.

McLean, S.R., S.R. Wolfe, and J.M. Nelson (1999), Spatially averaged flow over a wavy boundary revisited, J. Geophys. Res. 104, C7, 15,743-15,753.

Nikora, V.I., D.G. Goring, I. McEwan, and G. Griffiths (2001), Spatially-averaged open-channel flow over a rough bed, J. Hydraul. Eng. ASCE 127, 123-133.

Nikora, V., I. McEwan, S. McLean, S. Coleman, D. Pokrajac, and R. Walters (2007a), Double-averaging concept for rough-bed open-channel and overland flows: Theoretical background, J. Hydraul. Eng. ASCE 133, 873-883.

Nikora, V., S. McLean, S. Coleman, D. Pokrajac, I. McEwan, L. Campbell, J. Aberle, D. Clunie, and K. Koll (2007b), Double-averaging concept for rough-bed open-channel and overland flows: Applications, J. Hydraul. Eng. ASCE 133, 8, 884-895.

Pokrajac, D., L.J. Campbell, V.I. Nikora, I.K. McEwan, and C. Manes (2007), Quadrant analysis of persistent spatial velocity perturbations over squarebar roughness, Exp. Fluids, DOI: 10.1007/s00348-006-0248-0.

Pokrajac, D., I.K. McEwan, and V. Nikora (2008), Spatially averaged turbulent stress and its partitioning, Exp. Fluids, DOI: 10.1007/s00348-008-0463.

Raupach, M.R., and R.H. Shaw (1982), Averaging procedures for flow within vegetation canopies, Bound.-Layer Meteor. 22, 79-90.

Slattery, J.C. (1999), Advanced Transport Phenomena, Cambridge University Press, Cambridge.

Smith, J.D., and S.R. McLean (1977), Spatially averaged flow over a wavy surface, J. Geophys. Res. 83, 12, 1735-1746.

Whitaker, S. (1999), The Method of Volume Averaging, Kluwer Academic Publishers, Dordrecht.

Wilson, N.R., and R.H. Shaw (1977), A higher order closure model for canopy flow, J. Appl. Meteorol. 16, 1197-1205. 